\title{
AC 2009-2540: PRELIMINARY RESULTS FROM TEACHING STUDENTS HOW TO EVALUATE THE REASONABLENESS OF RESULTS
}

James Hanson, Rose-Hulman Institute of Technology

Patrick Brophy, Rose-Hulman Institute of Technology 


\title{
Preliminary Results from Teaching Students How to Evaluate the
} Reasonableness of Results James Hanson, Rose-Hulman Institute of Technology

Patrick D. Brophy, Ph.D., Rose-Hulman Institute of Technology

\begin{abstract}
For the past two years, the authors have combined training on metacognition with skills identified by practitioners to teach undergraduate civil engineering students how to evaluate the reasonableness of structural analysis results. Metacognition is a sequence of steps followed by a person to monitor and improve that person's own cognitive performance in an area. The practitioner skills taught fall into three categories: fundamental principles, approximations, and features of the solution. When combined, the training has resulted in a measurable increase in student ability to evaluate the reasonableness of results. This paper summarizes how the training was incorporated in the classroom and homework assignments. Results from surveys, observations from interviews, and exam scores are presented to show the effect of the training on attitude, behavior and cognition. The paper concludes with suggestions on how the training might be applied in other fields of engineering.
\end{abstract}

\section{Key Words}

Education Methods, Innovative Teaching Methods 


\title{
Preliminary Results from Teaching Students How to Evaluate the Reasonableness of Results
}

\author{
James H. Hanson, Ph.D. \\ Department of Civil Engineering, Rose-Hulman Institute of Technology \\ Patrick D. Brophy, Ph.D. \\ Department of Humanities and Social Sciences, Rose-Hulman Institute of Technology
}

\begin{abstract}
For the past two years, the authors have combined training on metacognition with skills identified by practitioners to teach undergraduate civil engineering students how to evaluate the reasonableness of structural analysis results. Metacognition is a sequence of steps followed by a person to monitor and improve that person's own cognitive performance in an area. The practitioner skills taught fall into three categories: fundamental principles, approximations, and features of the solution. When combined, the training has resulted in a measurable increase in student ability to evaluate the reasonableness of results. This paper summarizes how the training was incorporated in the classroom and homework assignments. Results from surveys, observations from interviews, and exam scores are presented to show the effect of the training on attitude, behavior and cognition. The paper concludes with suggestions on how the training might be applied in other fields of engineering.
\end{abstract}

\section{Motivation}

Advancements in hardware and software now enable practicing structural engineers to analyze and design large, complex structures that would have been impractical or impossible to design in past decades. These advancements also allow practicing engineers to analyze and design smaller structures at a much faster rate than in the past. With these increased abilities, however, come more opportunities for costly errors $^{1-2}$. Prior to the introduction of computers for structural analysis, practitioners developed skills for evaluating the reasonableness of their results. With the increasing reliance on computer analysis, those skills are more important than ever, but they are only sporadically documented ${ }^{3-7}$. If the skills are taught, it is typically through mentoring on the job rather than in the classroom. Therefore, the authors embarked on a project to determine how experienced structural engineers evaluate the reasonableness of their results and how to teach those skills in an undergraduate classroom.

To assist students in developing the skills necessary to evaluate the reasonableness of structural analysis results, the authors implemented instruction on metacognition. Metacognition is a sequence of steps followed by a person to monitor and improve that person's own cognitive performance in an area ${ }^{8-9}$. Metacognition has been used to improve student learning in reading, math and science for over twenty years ${ }^{10-12}$. 


\section{Background}

\section{Evaluation of Results - General}

Review of the literature produces little information on teaching undergraduate engineering students how to evaluate the results of their analysis or design. Grief ${ }^{13}$ describes several skills used to evaluate the performance of computer software: analytical methods of software testing, static analysis, and code inspection. However, the purpose of the paper is to demonstrate how those skills can be helpful in validating software. The author does not address how to teach those skills. Porter et al. ${ }^{14}$ also describe a tool for evaluating software, but their focus is on describing the specialized software and procedures used for the evaluations rather than how to teach the process. Other literature is focused on procedures for quality assurance that emphasize organizational controls and review procedures ${ }^{15-17}$. Again, however, the focus is on how to implement those controls, not how to teach them.

\section{Evaluation of Results - Structural Engineering}

Felton and Nelson, in the preface to Matrix Structural Analysis ${ }^{18}$, clearly define an important challenge facing practicing structural engineers:

"Yet, for all the power of the finite element method and computer-based analysis, the computational results are meaningful only if knowledgeable engineers can confirm their credibility. For this reason it is essential that engineers not only be able to understand the basic concepts that underlie the finite element method but, more to the point, be able to use these concepts to assess the quality of computer-based numerical analysis." (p. vii)

Unfortunately, a review of ten leading textbooks on structural analysis, including the one cited above, reveals that little to no formal instruction is offered on how to evaluate the reasonableness of results ${ }^{18-27}$. Therefore, the authors conducted interviews with practicing structural engineers to document the skills they use to evaluate results ${ }^{28-29}$. The interviews resulted in a wide variety of examples of skills (106 total) that can be grouped into seven categories:

Comparison (34 of 106). This category involves comparing two or more approaches or situations (e.g., hand calculations versus computer results, results from two different computer programs, results considering different conditions).

Rule of Thumb (7 of 106). This category involves use of simple formulas to predict member sizes or properties.

Visualization (5 of 106). This refers to visualizing the load path. Typically it involves making cuts and confirming that forces have a continuous path to the foundation.

Extreme (4 of 106). In some cases, the solution obtained is ridiculously large or small, thereby making it obviously incorrect. 
Previous Experience (25 of 106). These strategies can only be developed through experience. They typically involve recognizing a situation as similar to previous projects.

Field (14 of 106). This is one of the least preferred strategies. It means that the problem is discovered during or after construction.

Other (17 of 106). This category includes all of the other strategies used to discover a problem. Many of them are procedural (e.g., check model code used in the jurisdiction).

Of the seven categories, four can be taught (comparison, rule of thumb, visualization, and extreme). Rules of thumb pertain primarily to design where choices about members are made, and visualization pertains primarily to choices in structural system. Identifying extreme results can be done with minimal experience. Therefore, the authors focused on teaching comparisons.

\section{Metacognition}

Metacognition enables the students to monitor their own decision making processes as they learn how to implement the evaluation skills. Bielacyzc et al ${ }^{30}$ found that explicitly including metacognition training increased the learning and problem solving abilities of computer programming students. White and Frederiksen ${ }^{12}$ found that weaker students benefit even more than stronger students from metacognition training when learning physics concepts. Despite the long use of metacognition to improve student learning in the areas of reading, math and science, little literature exists about its use in engineering education.

\section{Classroom Implementation}

The authors chose to implement the training on metacognition and evaluation skills in the Structural Analysis I course. This course is mandatory for all civil engineering undergraduates and is taken in the junior year. The implementation included some classroom instruction, a new homework format, and a new type of exam question.

\section{Introduction to Metacognition}

The concept of metacognition is explicitly introduced during the second week of the course and takes a full lecture period. To motivate the process, the instructor uses the following demonstration. The instructor brings a six foot long flexible beam, supports, and weights to class. The instructor draws a common situation and asks the students to guess the deflected shape. Once the students have drawn their guess, the instructor demonstrates the actual behavior in front of the class. After several common situations, the instructor draws the situation shown in Figure 1, and asks students again to guess the deflected shape. The most common answer is shown in Figure 2. The instructor asks for a show of hands: which way will the right end go, up or down? Based on the majority response, the instructor applies the loads as in Figure $3 a$ or $3 b$ so that the beam behaves opposite from the majority response. The key to the demonstration is to put the students in a situation where their intuition is wrong. 


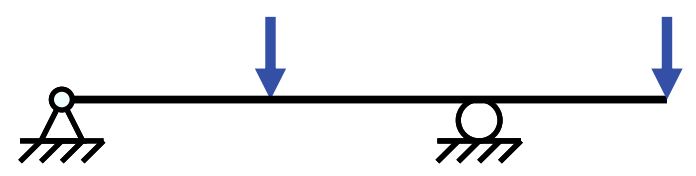

Figure 1. Example situation drawn by instructor. Students are asked to predict the deflected shape before the instructor demonstrates it in the classroom.

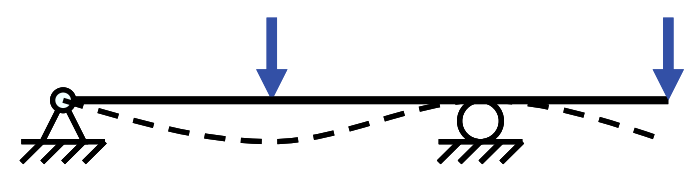

Figure 2. Most common student prediction of deflected shape.

(a)

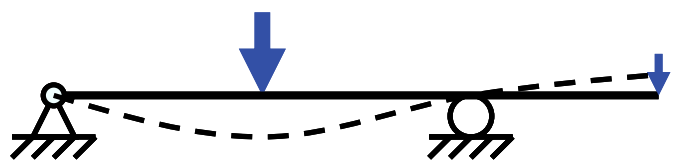

(b)

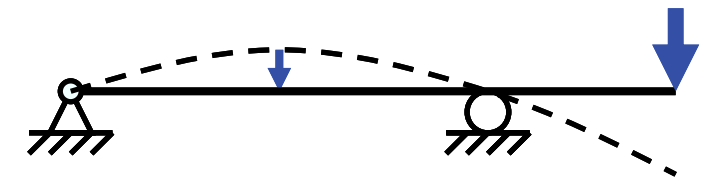

Figure 3. Actual deflected shape once instructor applies load to the model in the classroom. (a) If students predict right end will go down, instructor creates this situation. (b) If students predict right end will go up, instructor creates this situation.

The instructor then introduces the concept of metacognition. Since their prediction did not work out well, they should reflect on why they thought it was a good prediction. There was something they assumed or had previously experienced that suggested their prediction; what was it? Why was their assumption poor, or why did their previous experience not serve well in this situation? What would they do differently next time? This sequence of questioning and reflecting is metacognition. Periodically throughout the course, the instructor would lead the class through this process when the class' prediction proved far from the observed behavior.

\section{Teaching Evaluation Skills}

The Skills

After reviewing the information provided by practicing structural engineers, the authors decided to focus on tools within the "comparison" category for the structural analysis course. Specifically, the authors chose to emphasize three types of tools used 
frequently by the practitioners: fundamental principles, approximations, and features of the solution.

\section{Fundamental Principles}

Fundamental principles refer to the scientific principles that underlie engineering. In the case of structural analysis, the students learn the fundamental principles in the Statics and Mechanics of Materials courses, which are prerequisites for the Structural Analysis I course. The point emphasized to the students is that no matter how complex the model and no matter what assumptions they make, the fundamental principles must still be satisfied.

To motivate the value of fundamental principles in analysis of complex structures, the instructor uses the Eiffel Tower as a case study. The structure has over 10,000 members, but it was designed long before the invention of computers or hand calculators. It turns out that the analysis is simple when considering fundamental principles. Part of that case study is shown in Figure 4. The instructor shows the students how to determine the total axial force in one leg of the tower then asks what is the force in each of the four primary members that make up the leg. Because static equilibrium must be satisfied, their answer is bounded. The sum of the four forces must equal the total force they already calculated.

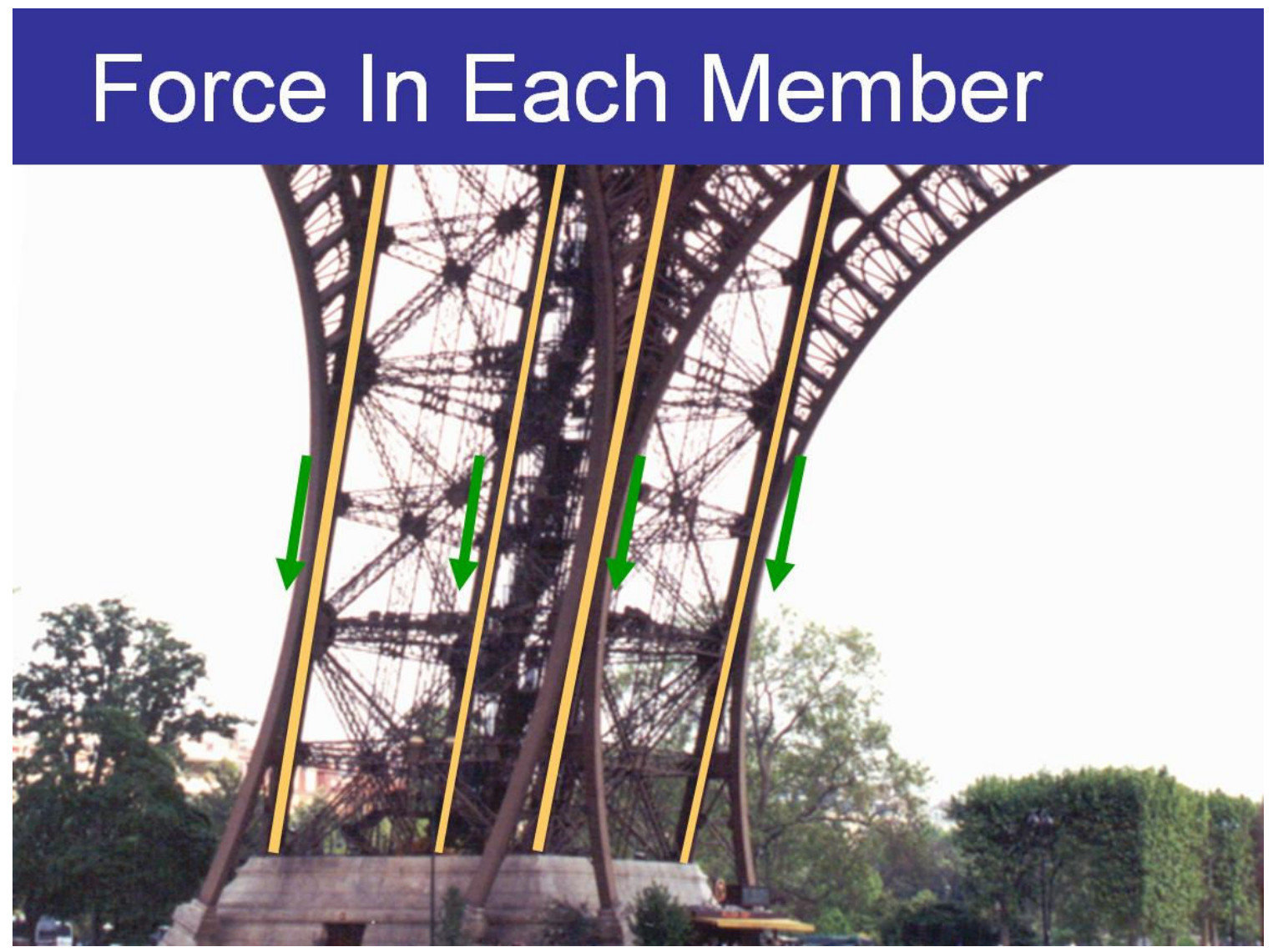


Figure 4. Slide from case study showing how to use fundamental principles to analyze one leg of the Eiffel Tower.

Approximations

The approximation skills taught in the Structural Analysis I course fall into two subcategories: simplified loading and assumptions. Sometimes the situation can be analyzed by hand calculations using the fundamental principles, but the loading conditions are so complex that the calculations are prone to errors. For example, the students are asked to calculate the maximum moment in a simply supported beam subjected to three equally spaced point loads of the same magnitude (a common structural situation). The applied load can be converted to an equivalent uniformly distributed load in order to quickly develop an approximate answer to compare with their solution to the more complicated situation (Figure 5). Because the approximation moves more of the load away from the center, the students are able to anticipate that the approximation will under-estimate the peak moment, which it does.

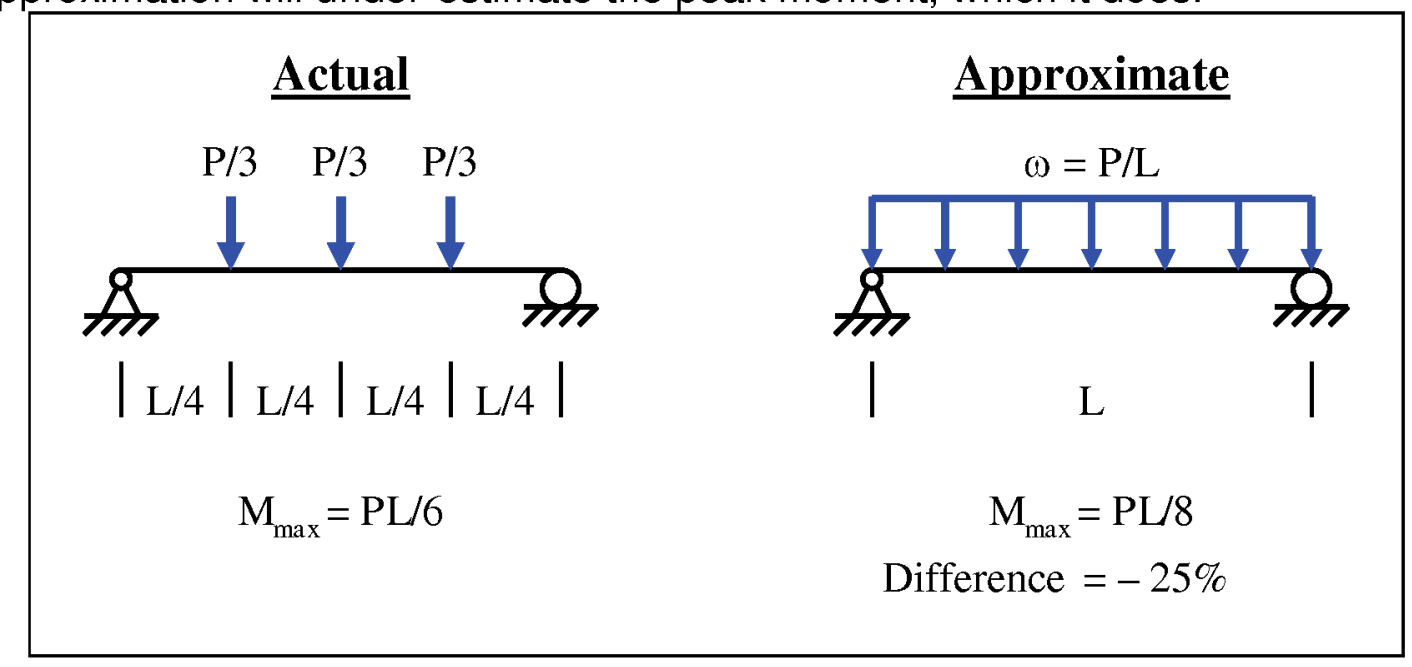

Figure 5. Analysis of a simply supported beam with three equally spaced point loads and of a beam with the equivalent uniform load as an approximation. The maximum internal moments are shown along with the error introduced by the approximation.

One of the primary reasons that practitioners use computer programs to perform structural analysis is that most structures are indeterminate. This means that there are more unknown internal forces than equations of equilibrium. To convert the situation back to one where hand calculations can be used, practitioners sometimes make assumptions about the internal forces. Common examples are the "portal method" and "cantilever method" for analyzing rigid frames subjected to lateral loads. Those methods are included in several undergraduate textbooks ${ }^{19,20,22,24,26}$. The instructor also provided recommended assumptions for analysis of braced frames (a common type of indeterminate, lateral load resisting frame) and indeterminate trusses.

Features of Solution

By considering boundary conditions, continuity, and fundamental principles, practitioners can anticipate features of a solution. These skills are especially helpful 
when reviewing graphical results such as internal force diagrams, influence lines, and deflected shapes. The instructor introduced specific skills where applicable throughout the course. For example, students can predict features of a moment diagram by sketching deflected shape first (Figure 6).

Situation: A simply supported beam with a cantilevered end experiences uniform distributed load.

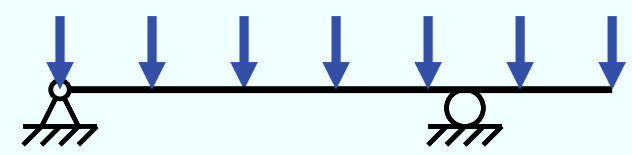

Find: Shape of the moment diagram.

\section{Solution:}

Since beam experiences uniform distributed load, expect diagram to be quadratic in all parts.

Use deflected shape to provide additional clues.

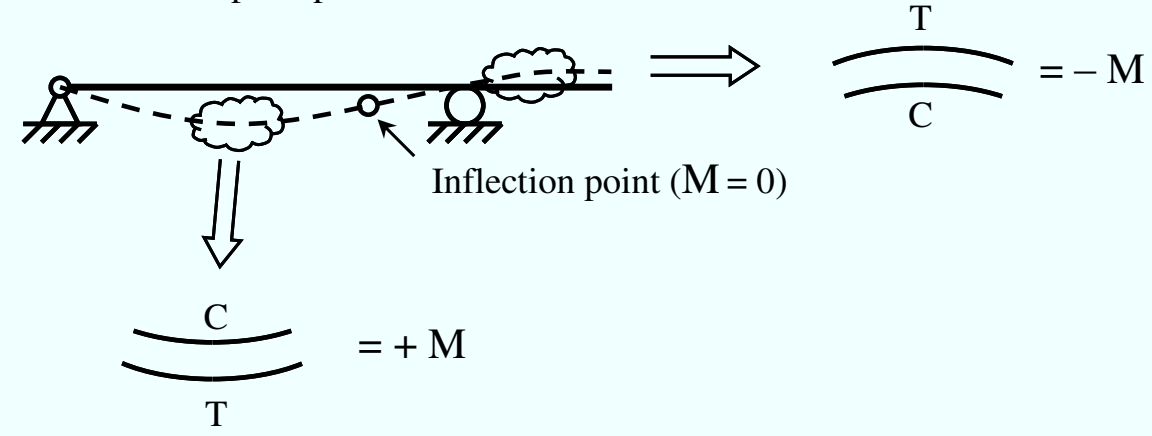

Resulting moment diagram:

\section{$\mathbf{M}$}

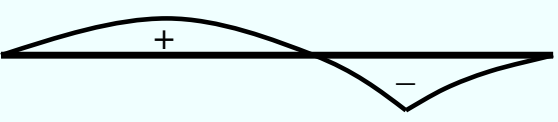

Figure 6. Example of how knowledge of deflected shape can be used to predict features of the moment diagram for a beam.

Reinforcement through Assignments

The authors developed a typical format for assignment problems in order to reinforce evaluation skills and to encourage practice of metacognition. For roughly the first twothirds of the course, the components are the following:

a) Guess a particular aspect of the solution chosen by the instructor.

b) Generate an approximate solution using the simplification or assumptions selected by the instructor.

c) Solve the problem as described in the textbook.

d) Identify expected features of the solution to the textbook problem. 
e) Verify that fundamental principles are satisfied in the solution to the textbook problem.

f) Use the results from parts b), d) and e) to make a comprehensive argument that the results from part c) are reasonable.

g) Compare guess from part a) with solution in part c). Explain why the guess was close to the actual solution (if that occurs) or why the guess was not close to the solution (if that occurs).

Approximately two-thirds of the way through the course, the instructor introduces a computer analysis program as a black box tool. The students do not study the direct stiffness method of analysis upon which the program is based. Instead, they use it to generate solutions to assignment problems in the following format:

a) Guess a particular aspect of the solution chosen by the instructor (typically deflected shape).

b) Generate an approximate solution (typically the textbook problem).

c) Use the computer to generate a solution.

d) Identify expected features of the computer solution (typically deflected shape or internal force diagrams).

e) Verify that fundamental principles (typically equilibrium) are satisfied in the computer results.

f) Use the results from parts b), d) and e) to make a comprehensive argument that the results from part c) are reasonable.

g) Compare guess from part a) with solution in part c). Explain why the guess was close to the actual solution (if that occurs) or why the guess was not close to the solution (if that occurs).

The authors incorporated the guess and reflect parts of the assignment, a) and g), to promote metacognitive behavior. The instructor did not grade students based on the quality of the guess because that would encourage them to complete part c) before part a). Instead, students received full credit for any guess. The instructor graded part g) based on candor in the reflection. One of the goals is to foster the behavior. As the students develop more experience, their guesses should improve. When practitioners make accurate predictions of the solution, we consider it part of the "previous experience" category of evaluation skills. Therefore, metacognitive activity should help the students develop the intuition attributed to "previous experience" faster.

\section{Assessment in Exams}

To further reinforce the evaluation skills, the authors developed special questions for the exams. The questions are multiple choice with one reasonable answer and three unreasonable answers. Students are instructed to select the most reasonable answer and to either justify why that answer is most reasonable or justify why the other three are not reasonable. In order to prevent the students from performing detailed analysis rather than practicing the evaluation skills taught in class, students have on average five minutes per problem. These special questions are put in a timed Part I of the exam. At the end of the time, students receive Part II which contains traditional problems. For the preliminary exams, Part I contains two problems and takes 10 minutes. Each term the 
instructor changes the preliminary exams and makes the old ones available for students to practice. An example problem with information on why three of the answers are not reasonable is presented in Figure 7 . For the final exam, Part I contains six problems and takes 30 minutes. The instructor reuses the same Part I from the final exam each year; therefore, those questions are not returned.

Situation: The indeterminate beam is subjected to distributed loads and a couple moment.

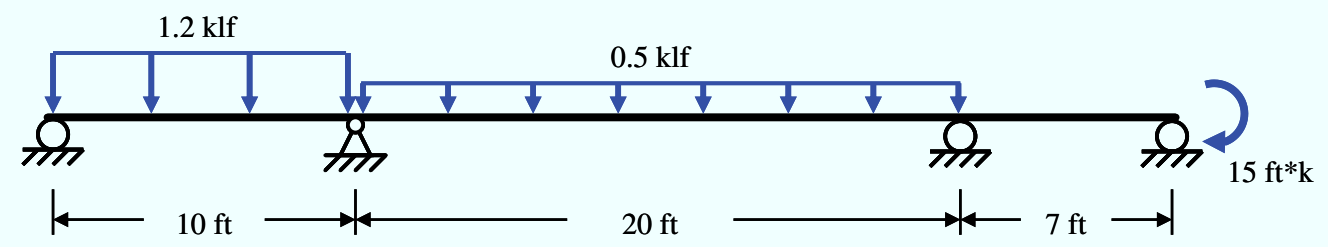

Find: Determine which displaced shape is most reasonable and justify your selection.

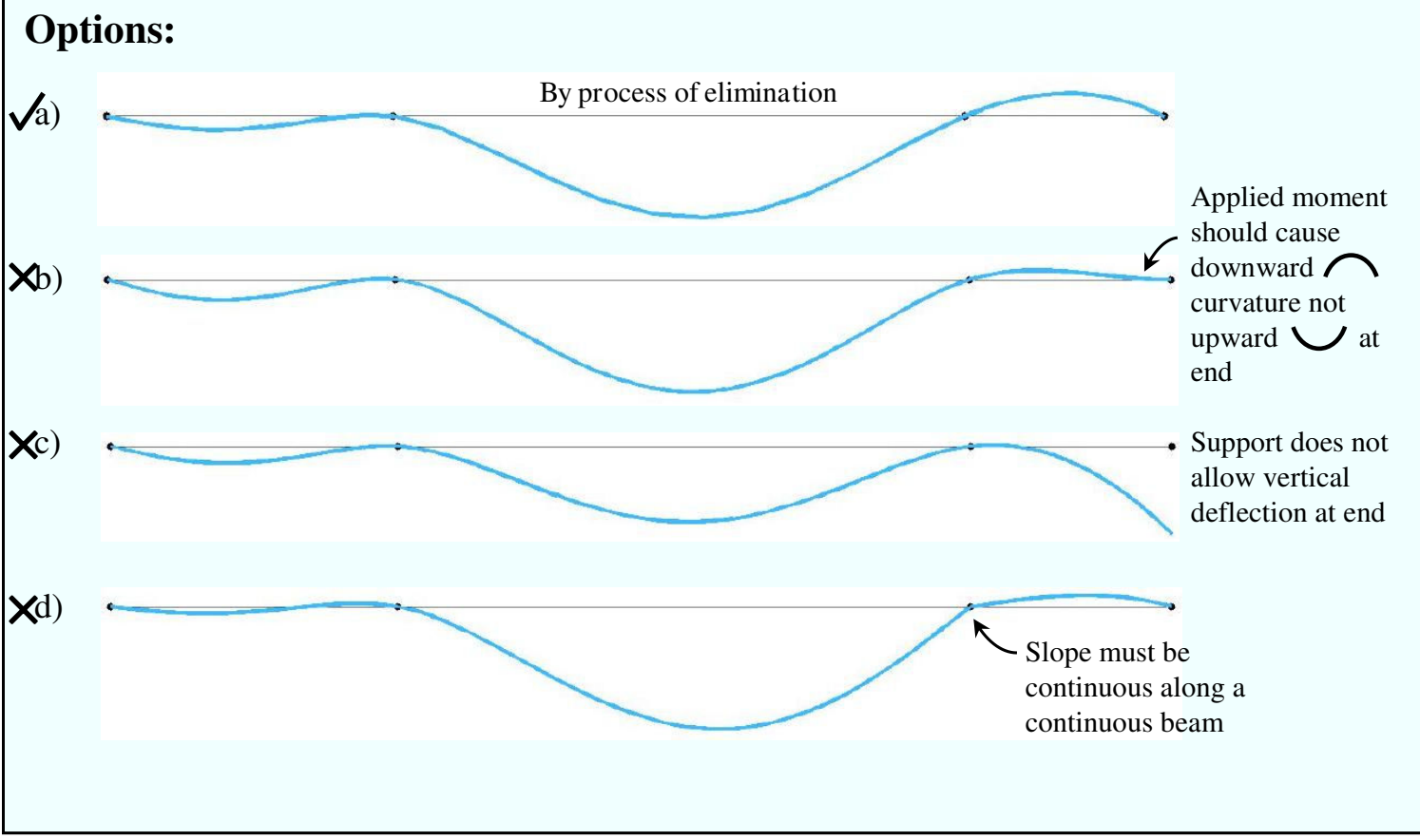

Figure 7. Example exam problem with the most reasonable answer selected and with justification why each of the other three answers are not reasonable.

\section{Results}

\section{Overview}

In order to assess the effectiveness of the training on evaluation of results and metacognition, the authors measured impact on the students in three areas: attitude, behavior, and cognition. To do so, the authors used several assessment tools: surveys, exams, and interviews. For a baseline, the instructors used the assessment tools with students taking the course without special instruction on evaluation of results or 
metacognition (Fall 2004). The subsequent year, the instructor introduced explicit training on evaluation of results (Fall 2005). Then the following year the instructor also added explicit training on metacognition (Fall 2006). Both topics continued to be part of the instruction (Fall 2007).

\section{Attitude}

In order for students to transition from student to practitioner (novice to expert), it is important for them to believe in the importance of evaluating their results. That transition can be helped by actively using metacognition. Therefore, the authors developed an exit survey to probe student attitudes about evaluating results and metacognition. The questions and results are presented in Table 1.

Table 1. Questions and responses about student attitudes from the survey at the end of the Structural Analysis I course.

\begin{tabular}{|c|c|c|c|c|c|c|c|c|}
\hline $\begin{array}{l}\text { Evaluating Results } \\
\text { Statement: }\end{array}$ & Year & $\begin{array}{c}\text { Response } \\
\text { Rate }\end{array}$ & $\begin{array}{c}\text { 4-Strongly } \\
\text { Agree }\end{array}$ & 3-Agree & 2-Disagree & $\begin{array}{l}\text { 1-Stronly } \\
\text { Disagree }\end{array}$ & Not Sure & Average \\
\hline Undergraduates should be able to & 2004 & $94 \%$ & 6 & 23 & 0 & 1 & 1 & 3.13 \\
\hline determine the reasonableness of a & 2005 & $98 \%$ & 16 & 29 & 1 & 0 & 0 & 3.33 \\
\hline solution to structural analysis & 2006 & $95 \%$ & 25 & 16 & 1 & 0 & 0 & 3.57 \\
\hline problems. & 2007 & $100 \%$ & 15 & 14 & 0 & 0 & 1 & 3.52 \\
\hline $\begin{array}{l}\text { Metacognition } \\
\text { Statement: }\end{array}$ & Year & $\begin{array}{c}\text { Response } \\
\text { Rate }\end{array}$ & $\begin{array}{l}\text { 4-Strongly } \\
\text { Agree }\end{array}$ & 3-Agree & 2-Disagree & $\begin{array}{l}\text { 1-Stronly } \\
\text { Disagree }\end{array}$ & Not Sure & Average \\
\hline Metacognition has improved my & 2006 & $95 \%$ & 4 & 25 & 3 & 1 & 9 & 2.97 \\
\hline performance in this course. & 2007 & $100 \%$ & 4 & 17 & 2 & 0 & 7 & 3.09 \\
\hline I am using or will use & 2006 & $95 \%$ & 9 & 23 & 2 & 0 & 8 & 3.21 \\
\hline metacognition in other courses. & 2007 & $100 \%$ & 7 & 11 & 1 & 0 & 11 & 3.32 \\
\hline
\end{tabular}

Based on student responses, the training on evaluation of results appears to have influenced student opinion about the importance of those skills. For the last two years, students have indicated strong agreement (3.5 out of 4.0) that undergraduates should be able to evaluate the reasonableness of results. In addition, the authors asked the Fall 2006 class to participate in a follow-up survey one year later. In that survey, $85 \%$ of the responding students (93\% response rate) either agreed or strongly agreed that fundamental principles, approximations, and features of the solution can be used to evaluate results in areas of civil engineering other than structural. Therefore, it appears that students believe in the importance of evaluating their results and the value of fundamental principles, approximations, and features of the solution in making those evaluations.

During the two iterations of the course where the instructor included training on metacognition, students indicated agreement (3.0 out of 4.0) that metacognition was helpful in the course. They also indicated solid agreement (3.2. out of 4.0) that they would use metacognition in other courses. Therefore, it appears that as a result of the training, students also believe in the utility of metacognitive activity. 


\section{Behavior}

In those same surveys, the authors asked students to report about their behavior with respect to evaluation of results and metacognition. The questions and results from the exit surveys are presented in Table 2. The questions and results from the follow-up survey given to the Fall 2006 class one year later are presented in Table 3.

Table 2. Questions and responses about student behaviors from the survey at the end of the Structural Analysis I course.

\begin{tabular}{|c|c|c|c|c|c|c|c|}
\hline $\begin{array}{l}\text { Metacognition } \\
\text { Question: }\end{array}$ & & $\begin{array}{c}\text { 5-Almost } \\
\text { Always }\end{array}$ & 4-Frequently & 3-Sometimes & 2-Rarely & 1-Never & Average \\
\hline How frequently do you use & 2006 & 3 & 21 & 16 & 2 & 0 & 3.60 \\
\hline \multirow[t]{2}{*}{ metacognition in this course? } & 2007 & 7 & 16 & 5 & 2 & 0 & 3.93 \\
\hline & & Yes & No & & & & \\
\hline Do you use metacognition more now & 2006 & $31(74 \%)$ & 11 & & & & \\
\hline than before you took this course? & 2007 & $22(74 \%)$ & 8 & & & & \\
\hline
\end{tabular}

Table 3. Questions and responses about student behaviors from students who took the Structural Analysis I course one year prior (in Fall 2006).

\begin{tabular}{|c|c|c|c|c|c|c|}
\hline $\begin{array}{l}\text { Evaluating Results } \\
\text { Question: }\end{array}$ & $\begin{array}{c}\text { 5-Almost } \\
\text { Always }\end{array}$ & 4-Frequently & 3-Sometimes & 2-Rarely & 1-Never & Average \\
\hline $\begin{array}{l}\text { I ... evaluate results in other areas of civil } \\
\text { engineering using one or more of the three } \\
\text { tools: fundamental principles, approximations, } \\
\text { and features of the solution. }\end{array}$ & 2 & 20 & 14 & 3 & 0 & 3.54 \\
\hline $\begin{array}{l}\text { I . . evaluate results in other areas of civil } \\
\text { engineering using other tools. }\end{array}$ & 0 & 11 & 18 & 7 & 3 & 2.95 \\
\hline $\begin{array}{l}\text { Metacognition } \\
\text { Question: }\end{array}$ & $\begin{array}{c}\text { 5-Almost } \\
\text { Always }\end{array}$ & 4-Frequently & 3-Sometimes & 2-Rarely & 1-Never & Average \\
\hline \multirow[t]{2}{*}{$\begin{array}{l}\text { How frequently do you use metacognition in } \\
\text { your courses? }\end{array}$} & 3 & 18 & 13 & 4 & 1 & 3.46 \\
\hline & $\begin{array}{l}\text { 5-Much } \\
\text { More }\end{array}$ & 4-More & $\begin{array}{l}\text { 3-Same } \\
\text { Amount }\end{array}$ & 2-Less & $\begin{array}{c}\text { 1-Much } \\
\text { Less }\end{array}$ & Average \\
\hline $\begin{array}{l}\text { As a results of the instruction in the Structural } \\
\text { Analysis I course, I now use metacognition ... } \\
\text { than before I took that course. }\end{array}$ & 1 & 22 & 16 & 0 & 0 & 3.61 \\
\hline
\end{tabular}

The results of the follow-up questionnaire show that the students are applying the same basic evaluation skills (fundamental principles, approximations, and features of the solution) to other areas of civil engineering more frequently than other evaluation skills, and that they are evaluating their results with the three basic evaluation skills almost frequently (3.5 out of 5.0). When asked what other evaluation skills they use in other areas of civil engineering, the skills the students described all fell into the categories of comparisons, previous experience, and extremes (see list in Background section). 
Therefore, according to student behavior, the basic skills used to evaluate structural analysis results can be used to evaluate results across civil engineering.

At the end of the Structural Analysis I course, the majority of students (74\%) indicated that they used metacognition more than before the start of the course. They responded that they used metacognition frequently (3.6-3.9 out of 5.0) in the course. One year later, they indicated that they still used metacognition more than before the course (3.6 out of 5.0) with only slightly less frequency (3.5 out of 5.0) in their courses. Therefore, the structure of the assignments and classroom instruction appear to have resulted in students' long-term use of metacognition.

The authors used interviews conducted by the non-engineer author to observe how students evaluate the reasonableness of results at the end of the course. Each interview consisted of a written problem and a computer problem and was conducted by the non-engineer author. Each year the students were divided into three or four groups with each group evaluating different problems. For the written problem, the students were presented with the problem statement and a solution generated by another engineer. They were asked to determine whether the other engineer's result was reasonable. They were encouraged to think-aloud as they worked. The role of the interviewer was to help the student remember to verbalize their thoughts and actions. For the computer problem, the students were presented with the problem statement and a computer model generated by another engineer. They were asked to determine whether the other engineer's computer analysis results were reasonable. Some of the results are presented in Table 4. Analysis of the interview data is still ongoing; therefore, results are not available for all groups for all years.

Table 4. Observations of student behavior from interviews where they evaluated the results of a hand analysis problem and a computer analysis problem.

\begin{tabular}{lcccc}
\hline & \multicolumn{2}{c}{ Hand Problem } & \multicolumn{2}{c}{ Computer Problem } \\
& $\begin{array}{c}\text { Use Quantitative } \\
\text { Eval Tool }\end{array}$ & $\begin{array}{c}\text { Use Qualitative } \\
\text { Eval Tool }\end{array}$ & $\begin{array}{c}\text { Use Quantitative } \\
\text { Eval Tool }\end{array}$ & $\begin{array}{c}\text { Use Qualitative } \\
\text { Eval Tool }\end{array}$ \\
\hline Ferm and Problem & $5 / 5$ & $4 / 5$ & $2 / 5$ & $5 / 5$ \\
Fall 2004 - Prob 1 & $11 / 11$ & $6 / 11$ & $5 / 11$ & $10 / 11$ \\
Fall 2004 Averages & $100 \%$ & $63 \%$ & $44 \%$ & $94 \%$ \\
Fall 2007 - Prob 1 & $5 / 5$ & $4 / 5$ & $2 / 5$ & $4 / 5$ \\
Fall 2007 - Prob 3 & $10 / 10$ & $3 / 10$ & $3 / 10$ & $10 / 10$ \\
Fall 2007 Averages & $100 \%$ & $47 \%$ & $33 \%$ & $93 \%$ \\
\hline
\end{tabular}

An interesting observation about student behavior is that when evaluating the written problem, students were more likely to use quantitative tools (fundamental principles and/or approximations). But when evaluating the computer problem, students were more likely to use qualitative tools (features of the solution). Ideally, students would use both types of tools to evaluate most results. The cause of this phenomenon is worthy of further investigation, but has not been undertaken by the authors. 


\section{Cognition}

Cognition is used here to refer to student knowledge and ability. The authors used data from the interviews and from the final exams to evaluate the impact of the training on student ability to evaluate the reasonableness of results. From the interviews, the authors calculated the rate at which the students correctly assess the written and computer results (Table 5).

Table 5. Observations of student ability during interviews to correctly evaluate the result of a hand analysis problem and a computer analysis problem.

\begin{tabular}{lccc}
\hline Term and Problem & $\begin{array}{c}\text { Correctly Assess } \\
\text { Hand Soln }\end{array}$ & $\begin{array}{c}\text { Correctly Assess } \\
\text { Computer Soln }\end{array}$ & $\begin{array}{c}\text { Identify Source of } \\
\text { Error }\end{array}$ \\
\hline Fall 2004 - Prob 1 & $3 / 5$ & $2 / 5$ & $0 / 2$ \\
Fall 2004 - Prob 3 & $7 / 11$ & $6 / 10$ & $1 / 6$ \\
Fall 2004 Averages & $63 \%$ & $53 \%$ & $13 \%$ \\
Fall 2007 - Prob 1 & $3 / 5$ & $3 / 4$ & $0 / 3$ \\
Fall 2007 - Prob 3 & $3 / 9$ & $7 / 10$ & $3 / 7$ \\
Fall 2007 Averages & $43 \%$ & $71 \%$ & $30 \%$ \\
\hline
\end{tabular}

The limited data from the interviews is inconclusive. Two of the Fall 2004 groups correctly assessed the problems in the interview with approximately the same frequency as two of the Fall 2007 groups. Of those that correctly assessed the computer problem, slightly more of the Fall 2007 students (those with evaluation of results training) were able to identify the source of the error.

The authors also gathered results from Part I of the final exam which is the same for all terms. The results are presented in Table 6 along with results from practitioners who took the same exam with the same time constraints.

Table 6. Performance on final exam questions requiring students to determine and justify the most reasonable answer.

\begin{tabular}{lccc}
\hline & & \multicolumn{2}{c}{ Correctly Identify } \\
Term & Number & Correctly Explain \\
Most Reasonable & Why Reasonable \\
\hline Fall 2004 & 34 & $50 \%$ & $49 \%$ \\
Fall 2005 & 48 & $67 \%$ & $70 \%$ \\
Fall 2006 & 44 & $66 \%$ & $69 \%$ \\
Fall 2007 & 30 & $69 \%$ & $69 \%$ \\
Practitioners & 8 & $92 \%$ & $72 \%$ \\
\hline
\end{tabular}

The exam results show a definite improvement of student ability to both correctly identify the most reasonable solution (increase from $50 \%$ to $66-69 \%$ ) and correctly 
explain why answers were reasonable or not (increase from $49 \%$ to $69-70 \%$ ). Addition of training on how to evaluate the reasonableness of results appears to have brought their ability to identify the most reasonable result significantly closer to practitioner level. The training also elevated the students to the same ability level as practitioners when explaining why answers are reasonable or not.

\section{Applicability Beyond Structural Engineering}

The evaluation tools of fundamental principles, approximations, and features of the solution work well for structural analysis results but not for structural design results. Evaluation of structural design results requires other tools from the categories listed earlier (comparison, rule of thumb, visualization, extreme, previous experience, field, other). Civil engineering students claim, however, that the same tools used for analysis of structural analysis results are useful for evaluating analysis results in other areas of civil engineering. The broad field of civil engineering includes structural, geotechnical, environmental, water resources, and transportation engineering. Therefore, if fundamental principles, approximations, and features of the solution apply to other areas of civil engineering, they probably apply to other fields of engineering.

As an example, consider how fundamental principles, approximations, and features of the solution can be applied in electrical engineering. Circuit analysis is governed by Ohm's Law and Kirchhoff's Current Law. Therefore, both laws must be satisfied when reviewing circuit analysis results. When performing analysis on a DC circuit with a capacitor, behavior can be approximated as an open circuit, and when performing analysis on a DC circuit with an inductor, behavior can be approximated as a short. Features of the solution can be a valuable tool when assessing frequency response of a filter. The amount of ripples in the frequency response of a filter relates to the order of the filter; therefore, the engineer can anticipate the amount of ripples just by considering the order of the filter.

\section{Conclusions}

The skills necessary to evaluate structural analysis results can be taught. Instruction on the tools of fundamental principles, approximations, and features of the solution resulted in measurable improvement in student ability to identify and justify the most reasonable solution to structural analysis problems. Student feedback suggests that those same tools can be effectively used to evaluate analysis results in other areas of civil engineering and possibly other fields of engineering. In addition, instruction on metacognition has had a measureable impact on students' use of metacognition as a tool to improve their learning in courses across the curriculum.

\section{Acknowledgements}


This study was made possible by the National Science Foundation, grant no. DUE0341212. The authors would like to thank the many engineers who contributed from the following firms: Applied Technology Corporation; Arup; Burns Engineering; Leslie E. Robertson Associates, R.L.L.P.; McComas Engineering, Inc.; MMS-A/E; Skidmore, Owings \& Merrill LLP; Spencer Engineering, Inc.; Thorton-Thomasetti Group; and Walter P. Moore and Associates, Inc. The authors are very grateful to the Office of Institutional Research, Planning, and Assessment at Rose-Hulman for their assistance in developing and administering the surveys. The authors would also like to thank Professor Mark Yoder from the Electrical and Computer Engineering Department at Rose-Hulman for assistance with the Electrical Engineering examples.

\section{References}

1. Puri, P. S. (Moderator) "Computer Misuse - Are We Dealing with a Time Bomb?", Forensic Engineering: Proceedings of the First Congress, Task Committee on Avoiding Failures Caused by Computer Misuse, Forensic Engineering Division, American Society of Civil Engineers, Minneapolis, MN, 1997, pp. 285-336.

2. Huston, E. T. "Are We Relying Too Much on Computers?", Structure Magazine, Joint publication of the National Council of Structural Engineers Associations (NCSEA), ASCE's Structural Engineering Institute (SEI), and the Council of American Structural Engineers (CASE); February 2007, pp. 7-8.

3. Betaque, A. D. and Rojiani, K. B. "Evaluation of Software for Analysis and Design of Reinforced Concrete Structures," Computing in Civil Engineering, 1st Congress, American Society of Civil Engineers, Washington, DC, 1994, pp. 466-473.

4. Blum, F. L. "Error Control in Engineering Design Programs," Computing in Civil Engineering: Computers in Engineering Practice, 6th Conference, American Society of Civil Engineers, Atlanta, GA, 1989, pp. 409-416.

5. Brenner, B., Gagnon, C., and Shah, C. K. "Quick Checks for Structural Computer Analysis," Computing in Civil Engineering, 1st Congress, American Society of Civil Engineers, Washington, DC, 1994, pp. 2073-2080.

6. Meyer, K. F. and Ressler, S. J. "A Tool But Not a Cruch: Using Design Software in an Undergraduate Structural Steel Course," Computing in Civil Engineering, 2nd Congress, American Society of Civil Engineers, Atlanta, GA, Volume 1, 1995, pp. 264-269.

7. Parmelee, R. A. "Computing and Design in Structural Engineering A Practicing Engineer's Point of View," Analysis and Computation, 11th Conference, American Society of Civil Engineers, Atlanta, GA, 1994, pp. 369-376. 
8. Brown, A. L. "Metacognitive Development and Reading," Theoretical Issues in Reading Comprehension, R. J. Spiro, B. C. Bruce and W. F. Brewer (Eds.), Erlbaum: Hillsdale, NJ, 1980, pp. 453-481.

9. Baker, L. and Brown, A. L. "Metacognitive Skills and Reading," Handbook of Reading Research, P. D. Pearson (Ed.), Longman: New York, NY, 1984, pp. 353394.

10. Flavell, J. H. "Metacognition and Cognitive Monitoring: A New Area of CognitiveDevelopmental Inquiry," American Psychologist, Volume 34, 1979, pp. 906-911.

11. Schoenfeld, A. H. Mathematical Problem Solving, Academic Press: San Diego, CA, 1985, 409p.

12. White, B. Y. and Frederiksen, J. R. "Inquiry, Modeling, and Metacognition: Making Science Accessible to All Students," Cognition and Instruction, Volume 16, Issue 1, 1998, pp. 3-118.

13. Greif, N. "Software Testing and Preventative Quality Assurance for Metrology," Computer Standards \& Interfaces, Volume 28, Issue 3, January 2006, pp. 286-296.

14.Porter, A., Yilmaz, C., Memon, A. M., Schmidt, D. C., and Natarajan, B. "Skoll: A Process and Infrastructure for Distributed Continuous Quality Assurance," IEEE Transactions on Software Engineering, Volume 33, Number 8, August 2007, pp. 510-525.

15. Lee, D.-E. and Arditi, D. "Total Quality Performance of Design/Build Firms Using Quality Function Deployment," Journal of Construction Engineering \& Management, Volume 132, Issue 1, January 2006, pp. 49-57.

16. Reis, E. "Quality Assurance in Computer Aided Design," Journal of Computing in Civil Engineering, Volume 12, Issue 2, April 1998, pp. 62-63.

17. Snee, R. D. "Eight Essential Tools," Quality Progress, Volume 36, Issue 12, December 2003, pp. 86-88.

18. Felton, L. P. and Nelson, R. B. Matrix Structural Analysis, John Wiley \& Sons, New York, NY, 1997, 700p.

19. Hibbeler, R. C. Structural Analysis, $6^{\text {th }}$ Edition, Prentice-Hall: Upper Saddle River, $\mathrm{NJ}, 2006,640 p$.

20. Kassimali, A. Structural Analysis, $3^{\text {rd }}$ Edition, Brooks/Cole Publishing: Pacific Grove, CA, 2005, 752p. 
21. Kassimali, A., Matrix Analysis of Structures, Brooks/Cole Publishing: Pacific Grove, CA, 1999, 592p.

22. Leet, K. M., Uang, C-M., and Gilber, A. M. Fundamentals of Structural Analysis, $3^{\text {rd }}$ Edition, McGraw-Hill: New York, NY, 2008, 784p.

23. McGuire, W., Gallagher, R. H., and Ziemian, R. D. Matrix Structural Analysis, $2^{\text {nd }}$ Edition, John Wiley \& Sons: New York, NY, 2000, 460p.

24. Nelson, J. K. and McCormac, J. C Structural Analysis: Using Classical and Matrix Methods, $3^{\text {rd }}$ Edition, John Wiley \& Sons: New York, NY, 2003, 525p.

25. Rajan, S. D. Introduction to Structural Analysis \& Design, John Wiley \& Sons: New York, NY, 2001, 700p.

26. Schodek, D. L. and Bechthold, M. Structures, $6^{\text {th }}$ Edition, Prentice-Hall: Upper Saddle River, NJ, 2008, 640p.

27. West, H. H. and Geschwindner, L. F. Fundamentals of Structural Analysis, $2^{\text {nd }}$ Edition, John Wiley \& Sons: New York, NY, 2002, 567p.

28. Hanson, J. H. and Brophy, P. D. "A Procedure for Gathering Experience from Practicing Engineers in order to Teach Experience in the Classroom," Proceedings, ASEE Annual Conference and Exposition, American Society for Engineering Education, Chicago, IL, 2006.

29. Hanson, J. H. "Quick Methods for Finding Errors in Structural Analysis and Design Results," Structure Magazine, Joint publication of the National Council of Structural Engineers Associations (NCSEA), ASCE's Structural Engineering Institute (SEI), and the Council of American Structural Engineers (CASE); June 2006, pp. 11-13.

30. Bielaczyc, K., Pirolli, P. L., and Brown, A. L. "Training in Self-Explanation and SelfRegulation Strategies: Investigating the Effects of Knowledge Acquisition Activities on Problem Solving," Cognition and Instruction, Volume 13, Issue 2, 1995, pp. 221252.

\section{Author Biographies}

Dr. James H. Hanson is an Assistant Professor of Civil Engineering at Rose-Hulman Institute of Technology. He has been teaching mechanics, structural engineering, and project management courses since 2000. His pedagogical research interests include efficiency of knowledge transfer and development of non-technical engineering skills. He was a 2006 recipient of the Ferdinand P. Beer \& E. Russell Johnston, Jr., Outstanding New Mechanics Educator Award from the Mechanics Division of ASEE.

Dr. Patrick D. Brophy is an Associate Professor of Psychology at Rose-Hulman Institute of Technology. $\mathrm{He}$ is a licensed clinical psychologist and has been teaching psychology courses for over 30 years. His research interests include assessment of memory and evaluation of disabilities. He has extensive experience developing and administering interview protocols. 